\title{
Non-Isothermal Degradation and Thermodynamic Properties of Pine Sawdust
}

\author{
Zephania Chaula $^{*}$, Geoffrey John' ${ }^{1}$ Mahir Said1', Samwel Manyele², Cuthbert Mhilu ${ }^{3}$ \\ ${ }^{1}$ Department of Sustainable Energy Science and Engineering, The Nelson Mandela African Institute of Science and Technology, \\ Arusha, Tanzania \\ ${ }^{2}$ Department of Chemical and Mining Engineering, University of Dares Salam, Dares Salam, Tanzania \\ ${ }^{3}$ Department of Mechanical and Industrial Engineering and Technology, University of Dar es Salam, Dar es \\ Salaam, Tanzania \\ Email: *chaulaz@nm-aist.ac.tz, geofrey.john@nm-aist.ac.tz,mahir@udsm.ac.tz,smanyele@udsm.ac.tz,cfmhilu@hotmail.com
}

How to cite this paper: Chaula, Z., John, G., Said, M., Manyele, S. and Mhilu, C. (2018) Non-Isothermal Degradation and Thermodynamic Properties of Pine Sawdust. Smart Grid and Renewable Energy, 9, 272-284.

https://doi.org/10.4236/sgre.2018.912017

Received: August 5, 2018

Accepted: December 25, 2018

Published: December 28, 2018

Copyright $\odot 2018$ by authors and Scientific Research Publishing Inc. This work is licensed under the Creative Commons Attribution International License (CC BY 4.0).

http://creativecommons.org/licenses/by/4.0/

\section{(c) (i) Open Access}

\begin{abstract}
The study of non-isothermal kinetics analyzed the reactivity of pine sawdust, while the thermodynamic properties analyzed energy consumed and released from the pine sawdust. The kinetic parameters were determined by analyzing mass loss of pine sawdust components by using Thermogravimeric analyzer. The cellulose has the highest conversion rate of $9.5 \% / \mathrm{min}$ at $610 \mathrm{~K}$ compared to hemicellulose and lignin, which are $5 \% / \mathrm{min}$ at $600 \mathrm{~K}$ and $2 \% / \mathrm{min}$ at $800 \mathrm{~K}$, respectively. The activation Energy for cellulose, hemicellulose and lignin was $457.644,259.876$, and $89.950 \mathrm{~kJ} / \mathrm{mol}$, respectively. The thermodynamic properties included the change of Gibbs free energy for cellulose and hemicellulose, which were -214.440 and $-30.825 \mathrm{~kJ} / \mathrm{mol}$ respectively, their degradation was spontaneous in forward direction, while change of Gibbs free energy for lignin was $207.507 \mathrm{~kJ} / \mathrm{mol}$, which is non-spontaneous reaction. The positive value of change of entropies for the active complex compounds formed from hemicellulose and cellulose is less stable, while the active complex compounds of lignin are characterized by a much higher degree of arrangement since its change of entropy is negative. The kinetic and thermodynamic properties show that pine sawdust is a good candidate for production of char since it is easier to remove hemicellulose through thermal process.
\end{abstract}

\section{Keywords}

Pine Sawdust, Non-Isothermal Kinetics, Thermo-Gravimetric Analysis, Activated Complex

\section{Introduction}

The use of wood fuel has increased worldwide due to emission of greenhouse 
gases and also depletion of fossil fuels. Sustainable production of wood fuel from forest can displace fossil fuels. Although burning of wood fuels releases carbon dioxide, the re-growth of the sustainably managed forest offset releases. Thus forest fuels can supply energy visually without net contribution greenhouse gases levels. Countries which have abundance forest resources can benefit in energy production through using wood waste such as sawdust. In most wood using industries the common wood byproducts that are used as a source of energy are sawdust, deformed stem and slabs [1]. The estimated amount of sawdust in Africa is $822 \mathrm{PJ} /$ year potential [2].

The combustion characteristics of solid fuel such as biomass are affected by its physical and chemical characteristics such as moisture content, bulk density, calorific value and its chemical composition. These are shown in Table 1. The bulk density and moisture content of wood biomass cause a storage problem, because it requires a large space and also equipment for handling [3]. Thermo-gravimetric analysis (TGA) is one of the techniques that are used to study the thermal behavior of solid fuels. TGA results are useful during application of the process such as pyrolysis, which is one of the promising thermo-chemical conversion methods, playing a vital role in biomass conversion.

Pine sawdust is one of the widely available sources of sawdust. The estimated amount in Tanzania is about 2,876,000 GJ/year [4] and mainly burnt in dumpsites. The resource is a lignocellulosic biomass which is made up of hemicellulose, cellulose and lignin. The percentage mass of these is mainly 20 - 35, 30 - 50 and $20-35 \mathrm{wt} \%$, respectively [5] [6].

When this biomass is subjected to a pyrolysis process, moisture evolution and biomass components decomposition occur. The moisture evolution is an endothermic process, whilst the decomposition of hemicellulose and lignin is exothermic. The case is contrary at higher temperature above $500^{\circ} \mathrm{C}$, here the hemicelluloses and lignin decomposition are endothermic and cellulose decomposition is exothermic [7]. During thermal degradation of biomass material, the biomass components are likely to react independently. However, most of the studies simplify and lump biomass as a single reactant as reported by Tsamba [8] and shown in Figure 1. A multi-component mechanism shown in Figure 2, taking into account the decomposition rate of hemicellulose, cellulose and lignin is considered. In the schematic mechanism presented in Figure 2, C is a biomass component (cellulose, hemicellulose or lignin) and $\mathrm{A}$ is active component. The scheme uses the kinetic and thermodynamic properties of individual components, by the use of TGA and employing Kissinger's method [9].

Table 1. Wood characteristics [3].

\begin{tabular}{cc}
\hline Characteristics & Value \\
\hline As received moisture & $40 \%-60 \%$ \\
Bulk density & $150-170 \mathrm{~kg} / \mathrm{m}^{3}$ \\
Calorific value & $15-19 \mathrm{MJ} / \mathrm{kg}$ \\
\hline
\end{tabular}




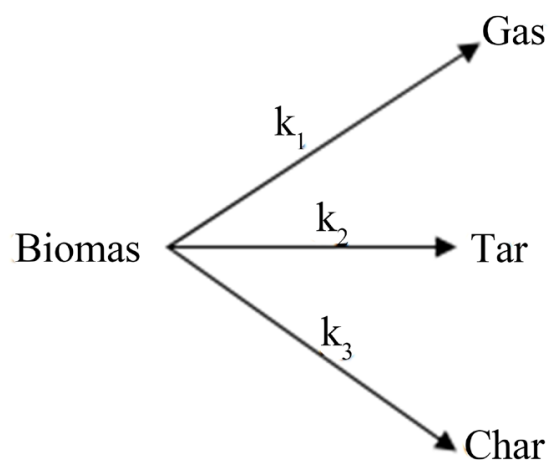

Figure 1. Proposed kinetic scheme of biomass decomposition.

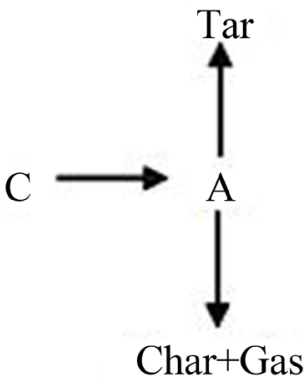

Figure 2. Multicomponent mechanism of pine components.

The Kissinger's method is suited when the analysis of the sample considered is to undergo a non-isothermal process. One of the distinguishing features of this method is its non-dependent on reaction mechanism for determination of activation energy, although the determination of the frequency factor assumes first order reaction mechanism [8].

The first law of thermodynamics state that, energy can never be created nor destroyed. This means the energy conversion processes do not have energy losses, except for transfer or converting to other form of energy. But the second law of thermodynamics stated that Energy conversion processes are accompanied by an irreversible increase in entropy, which leads to a decrease in available energy. Thus, even though the energy is conserved, the quality of energy decreases because energy is converted into a different form of energy, from which less work can be obtained. Due to these laws it important to analyze the thermodynamic characteristics of biomass as solid fuel, there are few researches done so far that describe the thermodynamic behavior of biomass and no one has explain about activated complex formation.

The thermodynamic properties of interest of biomass component decomposition to form active complex is an indication on whether the reaction occur or not, it shows the stability of the product and the amount of energy required for the reaction to take place. The activated complex is a collection of intermediate structures in the chemical reaction that persist while bonds are breaking and new bonds are forming. The formation of activated complex is depending on the 
analysis of change of the Gibbs free energy $\Delta G^{\ddagger}$, enthalpy $\Delta H^{t}$ and entropy $\Delta S^{*}$. The change of the Gibbs free energy $\Delta G^{ \pm}$indicates the total energy of the system from the approach of the reactant and the formation of the activated complex. This energy is caused by the changes of enthalpy $\Delta H^{\ddagger}$ and entropy $\Delta S^{\ddagger}$ for the formation of the activated complex. The change of the enthalpy indicates the energy differences between the activated complex and the reactant. When the difference is small, the formation of activated complex is favored since the potential energy barrier is low. The change of the activation entropy $\Delta S^{\star}$ shows how near the system is to its own thermodynamic equilibrium. In this situation, the material shows little reactivity, increasing the time taken to form the active complex. On the other hand, when high activation entropy values are observed, the material is far from its own thermodynamic equilibrium. In this case the reactivity is high, and the system can react faster to produce the active complex, which give shorter observation times [10]. This paper presents results on the kinetics and thermodynamics parameters of non-isothermal degradation of pine sawdust in nitrogen atmosphere.

\section{Methodology}

Pine sawdust samples for this study were obtained from SanyaJuu forest, West Kilimanjaro in Tanzania. The characterization was done by using Standard test methods ASTM 3172 and ASTM D3176-9 for establishing proximate and ultimate analysis respectively. Thermal degradation/decomposition and kinetic parameters of the biomass material was done by using thermo-gravimetric analyzer model NETZSCH STA 409 PC Luxx. Before thermo-gravimetric analysis, the sawdust sample was grounded to less than $1 \mathrm{~mm}$ size and oven dried at $378 \mathrm{~K}$ $\left(105^{\circ} \mathrm{C}\right)$ to a constant weight for removing the moisture. Then a purge gas, pure Nitrogen, was supplied to remove air in the thermo-gravimetric analyzer so as to avoid combustion during the experiment. After that a $30 \mathrm{mg}$ sample was put in the thermo-gravimetric analyzer, the heating medium was nitrogen $(99.95 \%$ purity) with flow rate $60 \mathrm{ml} / \mathrm{min}$ at a heating rate of $10 \mathrm{~K} / \mathrm{min}$. The samples were heated from room temperature of about $303 \mathrm{~K}\left(30^{\circ} \mathrm{C}\right)$ to $973 \mathrm{~K}\left(700^{\circ} \mathrm{C}\right)$, five iterations were done and arithmetic mean values were reported.

\subsection{Kinetic Study of Biomass Pyrolysis}

The pyrolysis rate is expressed by using Arrhenius Equation (1) and Equation (2), $k$ is the rate constant, which depends on temperature [8].

$$
\begin{gathered}
k=A \exp \left(-E_{a} / R T\right) \\
\mathrm{d} x / \mathrm{d} t=A f(x) \exp \left(-\frac{E_{a}}{R T}\right) \\
x=\frac{\left(w_{0}-w\right)}{\left(w_{0}-w_{\infty}\right)}
\end{gathered}
$$

where $x$ is the reacted fraction as shown in Equation (3), $T$ is the absolute tem- 
perature, $E_{a}$ is the activation energy, $A$ is the pre exponential factor, $R$ is the universal gas constant and $f(x)$ is the algebraic function depending on the reaction mechanism. When the temperature rises at a constant heating rate $(\beta)$ (expressed in Equation (4), the differentiation of Equation (4) will result into Equation (5) [8].

$$
\begin{gathered}
\beta=\frac{\mathrm{d} T}{\mathrm{~d} t} \\
\frac{\mathrm{d}^{2} x}{\mathrm{~d} t^{2}}=\left\{\frac{E_{a} \beta}{R T^{2}}+A f^{\prime}(x) \exp \left(-E_{a} / R T\right)\right\} \frac{\mathrm{d} x}{\mathrm{~d} t}
\end{gathered}
$$

The maximum rate occurs at a temperature $T_{\text {peak }}$, defined by equating Equation (5) to zero. Approximations from the calculations yield Equation (6).

$$
\ln \left(\frac{\beta}{T_{\text {peak }}^{2}}\right)=\ln \left(\frac{A R}{E_{a}}\right)-\left(\frac{E_{a}}{R T_{\text {peak }}}\right)
$$

Equation (6) is a straight line graph, of $\ln \left(\beta / T_{\text {peak }}^{2}\right) \mathrm{v} / \mathrm{s} 1 / T_{\text {Peak }}$, The line slope is $E_{a} / R$ and the intercept on the vertical axis is an $\ln \left(A R / E_{a}\right)$, which are used to determined $E_{a}$ and $A$.

The fractional pyrolysis of biomass component (hemicellulose, cellulose or lignin) is obtained by taking the ratio of the change mass of biomass component at time $\mathrm{t}$ and total reactive mass of as shown in Equation (7)

$$
x=\frac{\left(w_{0}-w\right)}{\left(w_{0}-w_{\infty}\right)}
$$

where $w_{0}$ is initial mass, wt is mass remains at time $t$ and $w_{\infty}$ is final weight remain.

Kissinger method allows to obtain the kinetic parameters of a solid-state reaction without knowing the reaction mechanism. It is a model-free non isothermal method where is no need to calculate Ea for each conversion value in order to evaluate kinetic parameters. This method allows to obtain the value of activation energy from a plot of $\ln \left(\beta / \mathrm{T}^{2} \mathrm{~m}\right)$ against $1000 / \mathrm{Tm}$ for a series of experiments at different heating rates $(\beta)$, where Tm is the temperature peak of the DTG curve.

\subsection{Thermodynamic Analysis of Biomass Material}

The thermodynamic parameters of entropy, heat of reaction and Gibbs free energy were determined using the theory of the active complex as reported by Turmanova [10] and Vlaev [11]. The entropy of the reaction is calculated by Equation (8):

$$
\Delta S^{\neq}=R\left(\ln A-\ln \frac{\sigma e \chi T_{\text {peak }}}{h}\right)
$$

where $\chi$ is the transmission coefficient which is unity for monomolecular reactions, $\sigma$ the Boltzmann constant, h the Plank constant, $e=2.7182$ is the Neper number and $\Delta S^{ \pm}$is the change of entropy for the formation of active complex from reactant. 
From the value of change of entropy $\Delta S^{\ddagger}$, conclusion can be drawn about the degree of arrangement and the complexity of the product formed to the initial reactants. The value of change of entropy can be either positive or negative, including zero. This is the criterion used to classify the chemical reactions as fast, slow or normal. If $\Delta S^{\ddagger}<0$, the reaction is classified as slow, it can be suggested that the product formed is more structured organized than the initial reactants, so its reaction is accompanied by a decrease of total entropy of the system. If $\Delta S^{\ddagger}>0$ for the reaction, it can be suggested that it is a reaction of dissociation of a complex molecules to simpler fragments, this reaction is classified as fast. When $\Delta S^{\star}=0$, the reaction is normal, in this reaction the structure of active complex formed does not accompanied with the significant changes from the initial reactant.

The change of enthalpy calculated is determined by way of Equation (9). This is the energy added to the system for the decomposition of biomass and it is always positive. The equation is used to obtained change of Gibbs free energy as shown in Equation (10) [12].

$$
\Delta H^{\neq}=E_{a}-R T_{\text {peak }}
$$

The change of Gibbs free energy $(\Delta G)$ reflects to the total energy increase of the system at the approach of the reactants and the formation of the products. This energy is influenced by two thermodynamic parameters: the changes of enthalpy $\Delta H^{t}$ and entropy $\Delta S^{\ddagger}$ of the product formed.

$$
\Delta G^{\neq}=\Delta H^{\neq}-T_{\text {peak }} \Delta S^{\neq}
$$

where; $T_{\text {peak }}$ is the peak temperature in the DTG curve.

\section{Results and Discussion}

\subsection{Proximate and Ultimate Analysis}

Table 2 shows results of the proximate and ultimate analysis of pine sawdust. Moisture content, volatile matter, fixed carbon and ash were determined. The pine sawdust is seen to be easily combustible since it contains high volatile matter. The high carbon content of 48.71 and hydrogen 5.99\%wt are vital for combustion process, while other components such as oxygen, nitrogen and sulfur are not favorable for fuel combustion [13].

The chemical analysis (ultimate analysis) was used to estimate the chemical composition of pine sawdust. Sulphur is neglected in this study since its amount is small in comparison with those of other elements. When this is taken into consideration, the chemical formula for the pine sawdust material is $\mathrm{C}_{23.74} \mathrm{H}_{32.03} \mathrm{O}_{16.16} \mathrm{~N}$.

\subsection{Thermo-Gravimetric Analysis Results}

The themogravimetric (TG) and Differential thermogravimetric (DTG) curves of decomposition of pine sawdust are presented in Figure 3 and Figure 4. According to the data obtained from the thermo-gravimetric analysis, thermal degradation of pine sawdust occurs in three main stages of mass loss, namely; 
Table 2. Characteristics of pine sawdust.

\begin{tabular}{cc}
\hline \multicolumn{2}{c}{ Proximate Analysis, dry basis (\%wt) } \\
\hline Moisture & 16.44 \\
Volatile Matter & 81.03 \\
Fixed Carbon & 18.60 \\
Ash & 0.37 \\
& Ultimate Analysis (\%wt) \\
Carbon & 48.71 \\
Hydrogen & 5.99 \\
Oxygen & 44.2 \\
Nitrogen & 2.39 \\
Sulfur & 0.28 \\
HHV MJ/kg & 15.10 \\
\hline
\end{tabular}

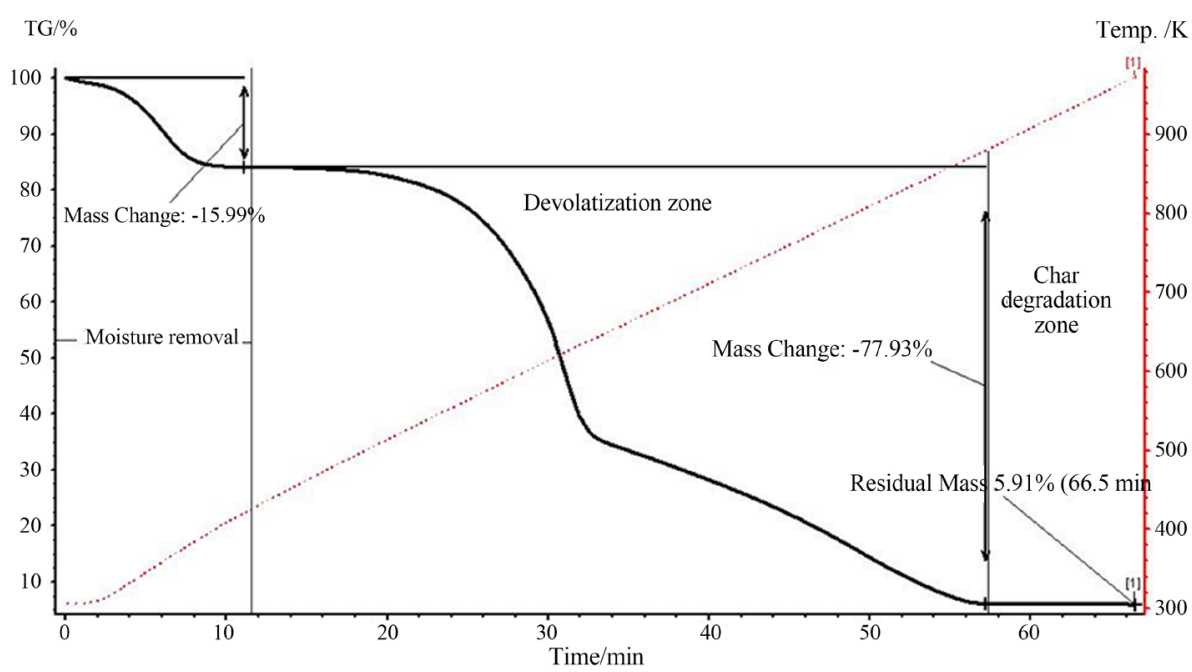

Figure 3. TG curve of pine sawdust.

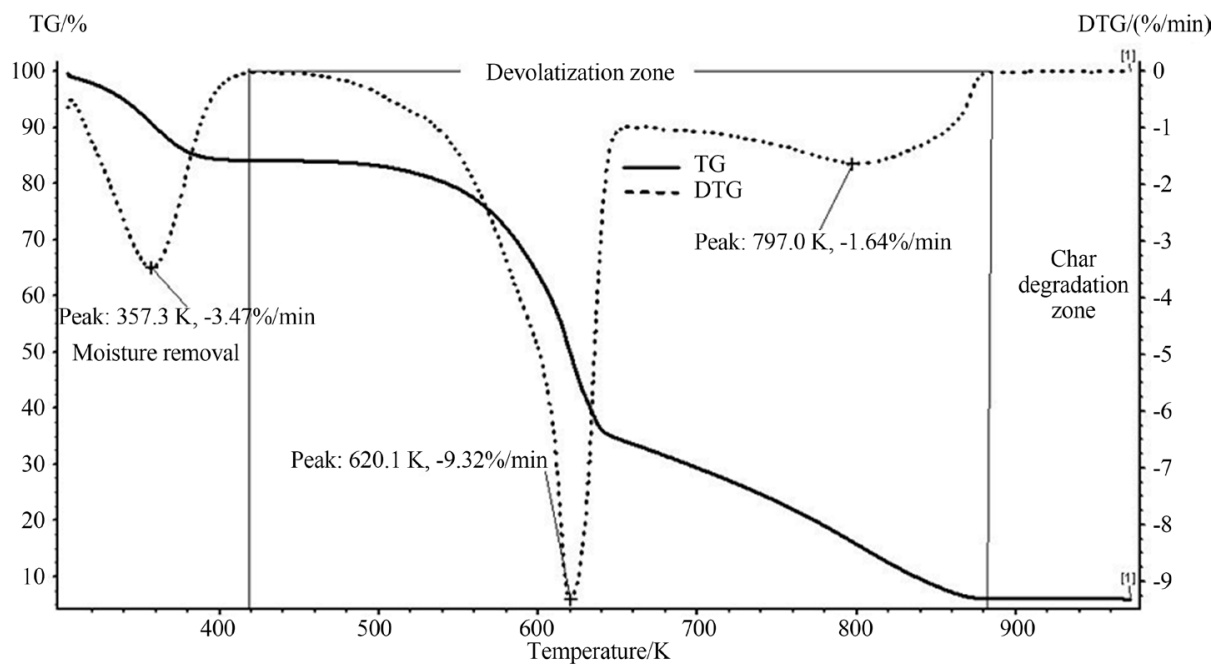

Figure 4. TG and DTG curves with biomass degradation zone. 
removal of moisture (drying), release of organic volatile matters (devolatization), and the degradation of char, as seen in Figure 3. The mass loss in the first stage takes place in the temperature range $303 \mathrm{~K}\left(30^{\circ} \mathrm{C}\right)$ up to $420 \mathrm{~K}\left(147^{\circ} \mathrm{C}\right)$, the mass loss was about $16 \%$ and it is associated with the evolution of sample moisture.

The other observed features of the thermal decomposition of pine sawdust can be explained on the basis of the decomposition behavior of its major constitutes: hemicellulose, cellulose and lignin. Moisture is released first at temperatures less than $420 \mathrm{~K}$, then hemicellulose degraded between 420 and $623 \mathrm{~K}$, cellulose from 548 to $653 \mathrm{~K}$, and finally lignin from 623 to $823 \mathrm{~K}$. The major mass loss of nearly $80 \%$ is due to the devolitization of the hemicellulose and cellulose as shown in Figure 3. The Degradation temperatures of hemicellulose, cellulose and lignin are overlapping as shown in Figure 4. The observed three peaks are due to the hemicellulose degradation at $590 \mathrm{~K}$, the cellulose at $620 \mathrm{~K}$ and lignin degradation at $797 \mathrm{~K}$.

The values of activation energy $\left(E_{a}\right)$ and pre-exponential factor $(A)$ were calculated according to the Kissinger's method, the values are given in Table 3. The activation energy for cellulose is higher at about $460 \mathrm{~kJ} / \mathrm{mol}$, than that of hemicellulse at $260 \mathrm{~kJ} / \mathrm{mol}$ and lignin at $90 \mathrm{~kJ} / \mathrm{mol}$. Hemicellulose decomposes at a lower temperature of $590 \mathrm{~K}$ and lignin at a temperature of $797 \mathrm{~K}$.

Besides the TG and DTG curves of pine sawdust pyrolysis, the Differential Scanning Calorimetry (DSC) curve shows the energy consumption level during the thermal degradation of pine. The results were plotted in Figure 5 and Figure 6. When the temperature was lower than $420 \mathrm{~K}\left(147^{\circ} \mathrm{C}\right)$, the DSC curve of the pine sawdust show that the reaction was endothermic, attributed to the removal of moisture when the sample was being heated up. With the temperature increasing greater than $420 \mathrm{~K}$, the DSC profile of pine sawdust show lower peak at a temperature of $823 \mathrm{~K}\left(550^{\circ} \mathrm{C}\right)$. This peak is due to crystallization of pine sawdust, as reported by Yang [7].

The process exhibits high exothermicity attributed by the charring process, although volatilization is endothermic reaction. The exothermic behavior of pine sawdust degradation is caused by tar cracking, lignin decomposition and dehydrocellulose decomposition to char and gas [14].

The total energy obtained from this process is $-4.59 \mathrm{MJ} / \mathrm{kg}$, this is the overall exothermic energy released during pine sawdust degradation.

\subsection{The Effect of Temperature on the Conversion Factor}

The rate of fractional pyrolysis of biomass $(\mathrm{d} x / \mathrm{d} t)$ was calculated from the TG

Table 3. Kinetic parameters for pine sawdust composition.

\begin{tabular}{cccc}
\hline Parameters & Hemicellulose & Cellulose & Lignin \\
\hline$T_{\text {peak }}, \mathrm{K}$ & 590 & 620 & 796.9 \\
$E_{a}, \mathrm{~kJ} / \mathrm{mol}$ & 259.9 & 457.6 & 90.0 \\
$A, \mathrm{~s}^{-1}$ & $4.365 \times 10^{23}$ & $3.33 \times 10^{38}$ & $1.768 \times 10^{5}$ \\
$k, \mathrm{~s}^{-1}$ & 4.280 & 1.414 & 0.167 \\
\hline
\end{tabular}




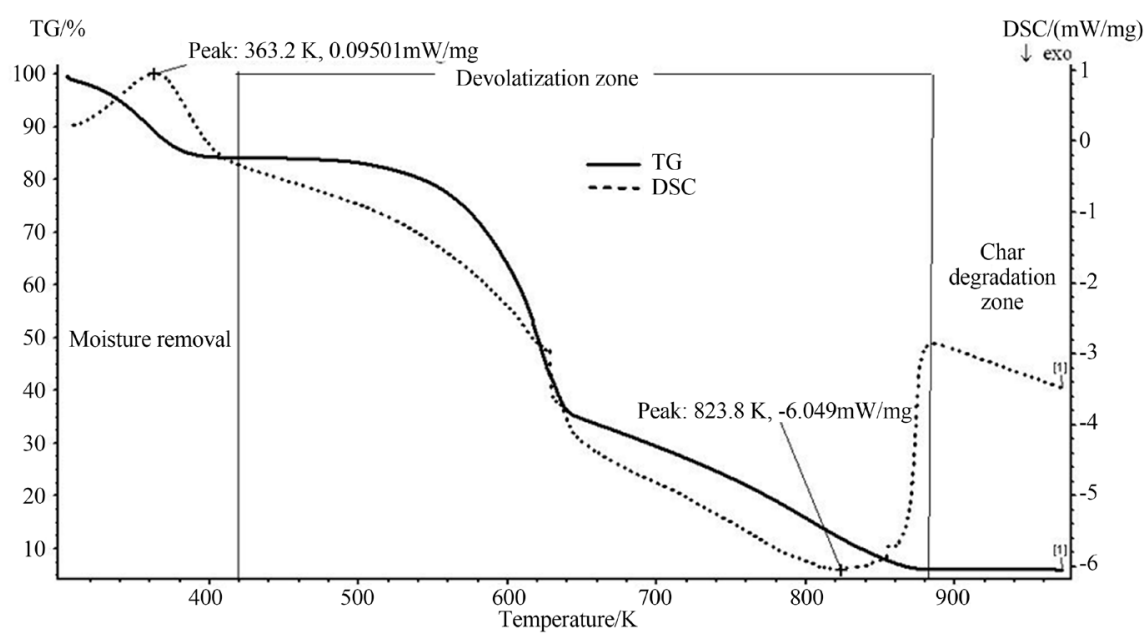

Figure 5. TG and DSC curves of pine sawdust.

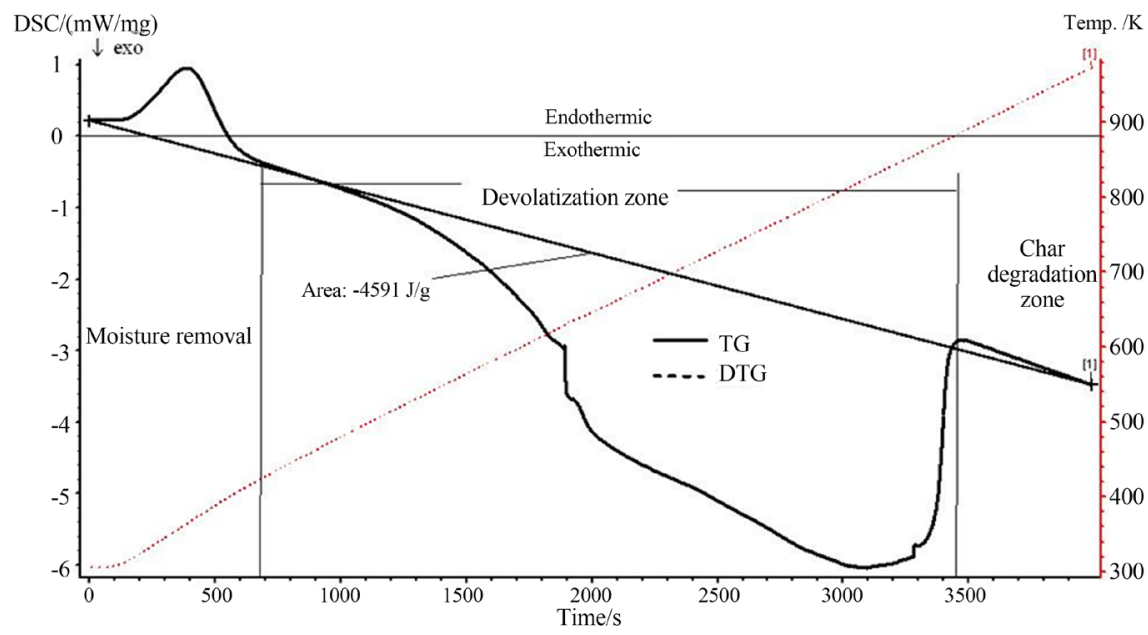

Figure 6. DSC curve with heat of reaction.

curve and the results are given in Figure 7. The biomass degradation was assumed to be first order. The first peak in Figure 7 is the removal of moisture from biomass at a degradation rate of $3.5 \% / \mathrm{min}$ at $350 \mathrm{~K}$, then followed by hemicellulose of $5(\% / \mathrm{min})$ at $590 \mathrm{~K}$. The highest degradation rate was observed on cellulose of $9.5(\% / \mathrm{min})$ at $610 \mathrm{~K}$, while least degradation rate was for lignin of 2 $(\% / \mathrm{min})$ at $800 \mathrm{~K}$. The range of degradation temperature of cellulose, hemicellulose and lignin were $500-750 \mathrm{~K}, 440-750 \mathrm{~K}$ and $450-880 \mathrm{~K}$, respectively.

In Figure 7, the biomass components were assumed to decompose independently of one another as stated by Di Blasi [15]. But the results revealed that degradation temperatures were overlapping to one another; this also was reported by [8] that lignocellulosic biomass samples show the overlapping peaks during thermal decomposition. The different thermal degradation behavior of cellulose, hemicellulose and lignin are attributed to their individual chemical nature. The hemicellulose has random amorphous structure, which contains heteropolysacharides and thermally degrades at low temperature. While cellulose is a linear 


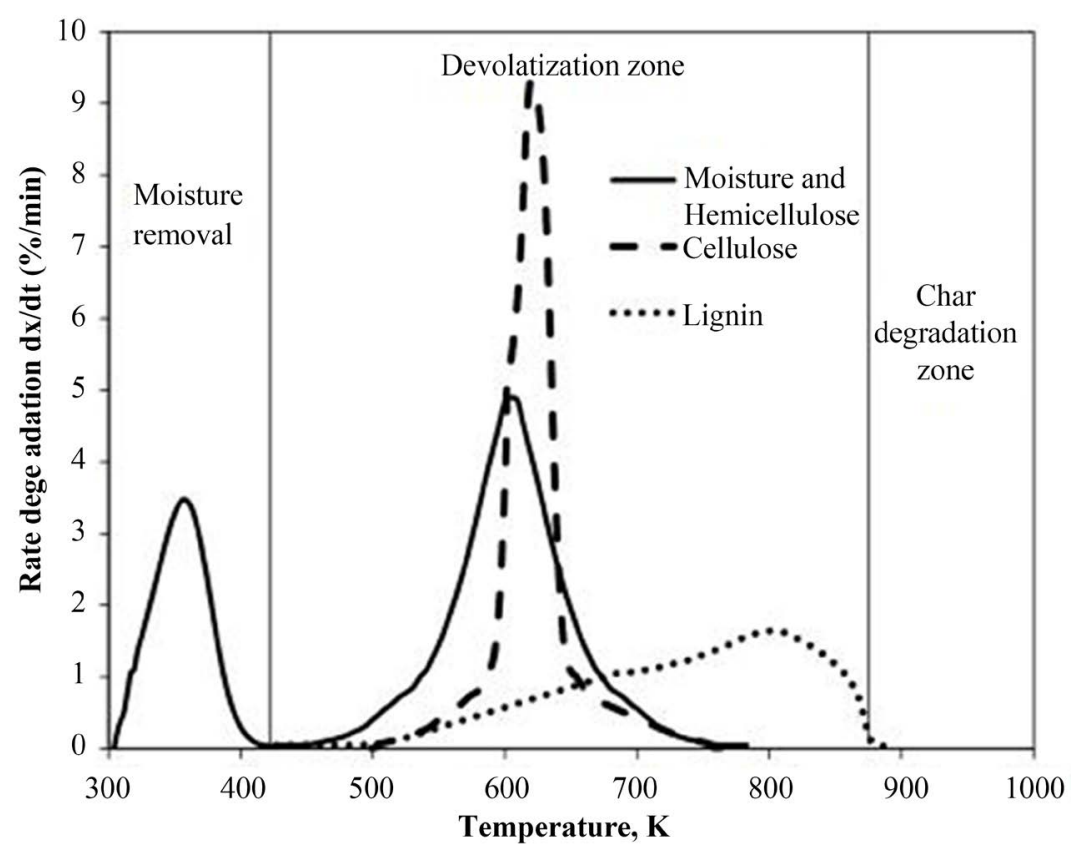

Figure 7. The variation of conversion factor with temperature.

polymer of glucose, which contains crystalline and amorphous region, the crystalline is resistant to heat, which makes the cellulose to degrade at $513 \mathrm{~K}-623 \mathrm{~K}$ producing an hydrocellulose and levoglucosan. Lignin is highly branched, mononuclear aromatic polymer forming a lignocellulosic complex in the biomass. The thermal decomposition of lignin occurs at $553 \mathrm{~K}-773 \mathrm{~K}$ yielding phenol via cleavage of ether and carbon-carbon linkages [16].

\subsection{Thermodynamic Analysis Results}

The thermodynamic properties of the biomass components, the values of change of entropy $\left(\Delta S^{\ddagger}\right)$, enthalpy $\left(\Delta H^{*}\right)$ and Gibbs energy $\left(\Delta G^{\star}\right)$ were calculated from Equation (8) and Equation (9), and the results are shown in Table 3. The change of entropy for hemicellulose and cellulose were positive, this shows that their products (active complex) are less organized structure than the initial reactant, while the change of entropy of lignin was negative, which show that the product is more organized structure than the lignin itself. The data obtained in Table 4 for the enthalpy change $\left(\Delta H^{\ddagger}\right)$ show that high energy is required for the decomposition of cellulose since its potential energy barrier is high of $452 \mathrm{~kJ} / \mathrm{mol}$, as compared to energy added to decompose hemicellulose $(255 \mathrm{~kJ} / \mathrm{mol})$ and lignin $(83 \mathrm{~kJ} / \mathrm{mol})$. The Gibbs free energies of hemicellulose and cellulose are negative, therefore the degradation at their peak temperature is spontaneous in forward reaction, while the Gibbs free energy of lignin is positive, and so it has slow degradation.

\section{Conclusions}

The pine sawdust has high volatile matter of $81 \mathrm{wt} \%$, whereas coal has about 
Table 4. Thermodynamic properties for pine sawdust.

\begin{tabular}{cccc}
\hline Parameters & Hemicellulose & Cellulose & Lignin \\
\hline$T_{\text {peak }}, \mathrm{K}$ & 590 & 620 & 796.9 \\
$\Delta S^{\ddagger}, \mathrm{J} / \mathrm{mol} \mathrm{K}$ & 193.669 & 478.137 & -160.805 \\
$\Delta H^{\ddagger}, \mathrm{kJ} / \mathrm{mol}$ & 254.971 & 452.464 & 83.440 \\
$\Delta G^{\ddagger} \mathrm{kJ} / \mathrm{mol}$ & -30.825 & -214.440 & 207.507 \\
\hline
\end{tabular}

$20 \mathrm{wt} \%$ [17]. The high volatility of biomass offers important advantages as a combustion feedstock and high reactivity of both the fuel and the resulting char. The ash content of pine sawdust is $0.37 \mathrm{wt} \%$, which is much lower than that of bituminous coal at $53.802 \mathrm{wt} \%$ [17]. The lower ash content avoids the risk of bed agglomeration in fluidized bed boilers, thus reducing fouling, slagging and super-heater corrosion [18]. Thus received calorific value was $15.10 \mathrm{MJ} / \mathrm{kg}$, partly due to high oxygen content of $44.2 \mathrm{wt} \%$. High oxygen content lowers the heating value [19]. The biomass calorific value can be increased to more than $20 \mathrm{MJ} / \mathrm{kg}$ through biomass pretreatment process such as steam explosion.

The activation energy of lignin is lower than that of cellulose and hemicellulose, but decomposes at higher temperature of $797 \mathrm{~K}$, while the hemicellulose and cellulose decompose at lower temperature of $590 \mathrm{~K}$ and $620 \mathrm{~K}$ respectively, indicating that hemicellulose and cellulose are more reactive than lignin. Cellulose has a higher conversion rate of $9.5 \% / \mathrm{min}$ at $610 \mathrm{~K}$ than hemicellulose $5 \% / \mathrm{min}$ at $590 \mathrm{~K}$ and lignin $2 \% / \mathrm{min}$ at $797 \mathrm{~K}$. Lignin has a wider temperature range of degradation of about $450 \mathrm{~K}$ - $880 \mathrm{~K}$ than the other biomass components. The degradation temperatures of biomass components are overlapping to form single peak as observed in Figure 4 and the individual peak of biomass components is shown in Figure 7. Hemicellulose is degradable at a temperature of $590 \mathrm{~K}$, such that pine sawdust can be used in torrefaction for production of char, at process that occurs at $480 \mathrm{~K}$ to $600 \mathrm{~K}$ [20].

The thermodynamic parameters (entropy, enthalpy and Gibbs free energy) of active complex of pine sawdust show that lignin is more stable and the least stable component is hemicellulose. Generally, the pine sawdust thermal decomposition is exothermic process and the overall heat of reaction is $-4.59 \mathrm{MJ} / \mathrm{kg}$.

\section{Acknowledgements}

The authors wish to thank the Nelson Mandela African Institution of Science and Technology and Commission for Science and Technology, Tanzania for their generous financial and materials support rendered to allow this research work to be conducted. The University of Dar es Salaam, Energy laboratories, staff and students are highly acknowledged towards this research.

\section{Conflicts of Interest}

We declare that we have no competing interests. We also confirm that there are 
no known conflicts of interest associated with this publication and there has been no significant financial support for this work that could influenced its outcome. The manuscript has been read and approved by all named authors.

\section{References}

[1] Rose, S., Remedio, E. and Trossero, M. (2009) Criteria and Indicator for Sustainable Wood Fuels. Case Studies from Brazil, Guyana, Nepal, Philippines and Tanzania. Food and Agriculture Organization of the United Nations, Rome, Italy.

[2] Stecher, K., Brosowski, A. and Thrän, D. (2013) Biomass Potential in Africa. International Renewable Energy Agency, Abu Dhabi, United Arab Emarates.

[3] Kofman, P. (2006) Quality Wood Chip Fuel. Denish Forestry Extension. Bredsten, Denmark.

[4] Wilson, L., Yang, W., Blasiak, W., John, G. and Mhilu, C. (2011) Thermal Characterization of Tropical Biomass Feedstocks. Journal of Energy Conversion and Management, 52, 191-198. https://doi.org/10.1016/j.enconman.2010.06.058

[5] Mohan, D., Pittman, C. and Steele, P. (2006) Pyrolysis of Wood/Biomass: A Critical Review. Journal of Energy and Fuels, 20, 848-889. https://doi.org/10.1021/ef0502397

[6] Raveendran, K., Ganesh, A. and Khilar, K. (1995) Influence of Mineral Matter on Biomass Pyrolysis Characteristics. Journal of Fuel, 74, 1812-1822. https://doi.org/10.1016/0016-2361(95)80013-8

[7] Yang, H., Yan, R., Chen, H., Lee, D. and Zheng, C. (2007) Characteristics of Hemicellulose, Cellulose and Lignin Pyrolysis. Journal of Fuel, 86, 1781-1788. https://doi.org/10.1016/j.fuel.2006.12.013

[8] Tsamba, A. (2008) Fundamental Study of Two Selected Tropical Biomass for Energy Coconut and Cashew Nut Shells. Dissertation, Royal Institute of Technology, Stockholm.

[9] Criado, J. and Ortega, A. (1986) Non Isothermal Transformation Kinetics Remarks on Kissinger's Method. Journal of Non Crystalline Solid, 87, 302-311. https://doi.org/10.1016/S0022-3093(86)80004-7

[10] Turmanova, S., Genieva, S. and Vlaev, L. (2011) Kinetics of Non-Isothermal Degradation of Some Polymer Composites: Change of Entropy at the Formation of the Active Complex from the Reagents. Journal of Thermodynamics, 2011, Article ID 605712. https://doi.org/10.1155/2011/605712

[11] Vlaev, L., Markovska, I. and Lyubchev, L. (2003) Non-Isothermal Kinetics of Pyrolysis of Rice Husk. Journal of Thermochimicaacta, 406, 1-7. https://doi.org/10.1016/S0040-6031(03)00222-3

[12] Matsoukas, T. (2012) Fundamentals of Chemical Engineering Thermodynamics, Edwards Brothers Malloy in Ann Arbor, Michigan, US.

[13] Bridgwater, A., Meier, D. and Radlein, D. (1999) An Overview of Fast Pyrolysis of Biomass. Journal of Organic Geochemistry, 30, 1479-1493. https://doi.org/10.1016/S0146-6380(99)00120-5

[14] Park, W. (2008) A Study of Pyrolysis of Charring Material and Its Application to Fire Safety and Biomass Utilization. Dissertation, University of Michigan.

[15] Di Blasi, C. (2008) Modeling Chemical and Physical Processes of Wood and Biomass Pyrolysis. Journal of Progress in Energy and Combustion Science, 34, 47-90. https://doi.org/10.1016/j.pecs.2006.12.001

[16] Basu, P. (2010) Biomass Gasification and Pyrolysis Practical Design and Theory. 
Elsevier Inc., United State.

[17] Mashingo, P. and John, G. (2011) Characteristics Properties of Tanzanian Coal for High Temperature Gasification.2nd International Conference on Advances in Engineering and Technology, Makerere University, Uganda, 13 June 2011.

[18] Patel, B. and Gami, B. (2012) Biomass Characterization and Its Use as Solid Fuel for Combustion. Iranica Journal of Energy and Environment, 3, 123-128.

[19] Demirbas, A. (2004) Combustion Characteristics of Different Biomass Fuel. Journal of Progress in Energy and Combustion Science, 30, 219-230. https://doi.org/10.1016/j.pecs.2003.10.004

[20] Sadaka, S. and Negi, S. (2009) Improvement of Biomass Physical and Thermochemical Characteristics via Torrefaction Process. Journal of Environmental and Sustainable Energy, 28, 427-434. https://doi.org/10.1002/ep.10392

\section{Nomenclature}

$A$ : Pre-exponential factor $\left(\mathrm{s}^{-1}\right)$

$E_{a}$ : Activation energy $(\mathrm{kJ} / \mathrm{mol})$

$f(x)$ : Conversion function (-)

$k$. Reaction constant $\left(\mathrm{s}^{-1}\right)$

$n$ : Order of reaction

$R$ : Universal gas constant $(\mathrm{J} / \mathrm{mol} \cdot \mathrm{K})$

TG: Thermogravimetric

DTG: Differential Thermogravimetric

DSC: Differential Scanning Calorimetry

T: Temperature (K)

$t$. Time (s)

$T_{\text {peak }}$ : Peak temperature (K)

$x$ : Degree of conversion (-)

$\beta$ : Heating rate $(\mathrm{K} / \mathrm{min})$

$\Delta G$ : Gibbs free energy $(\mathrm{J} / \mathrm{mol})$

$\Delta H$ : Enthalpy change $(\mathrm{J} / \mathrm{mol})$

$\Delta S$ : Entropy change $(\mathrm{J} / \mathrm{mol})$ 